This is the final peer-reviewed accepted manuscript of:

S. Voci, B. Goudeau, G. Valenti, A. Lesch, M. Jović, S. Rapino, F. Paolucci, S. Arbault, and N. Sojic

Surface-Confined Electrochemiluminescence Microscopy of Cell Membranes

J. Am. Chem. Soc. 2018, 140, 14753-14760

The final published version is available online at:

https://pubs.acs.org/doi/10.1021/jacs.8b08080

Rights / License:

The terms and conditions for the reuse of this version of the manuscript are specified in the publishing policy. For all terms of use and more information see the publisher's website.

This item was downloaded from IRIS Università di Bologna (https://cris.unibo.it/)

When citing, please refer to the published version. 


\title{
Near-field Electrochemiluminescence Microscopy of Cell Membranes
}

\author{
Silvia Voci, ${ }^{\dagger}$ Bertrand Goudeau, ${ }^{\dagger}$ Giovanni Valenti, ${ }^{\ddagger}$ Andreas Lesch,,${ }^{\S}$ Milica Jović, ${ }^{\S}$ Stefania \\ Rapino, ${ }^{\ddagger}$ Francesco Paolucci, ${ }^{\ddagger}$ Stéphane Arbault, ${ }^{\dagger}$ and Neso Sojic ${ }^{*}{ }^{\dagger}$ \\ ${ }^{\dagger}$ University of Bordeaux, Bordeaux INP, ISM, UMR CNRS 5255, 33607 Pessac, France. \\ $\$$ Department of Chemistry “G. Ciamician”, University of Bologna, Via Selmi 2, 40126 Bologna, Italy. \\ $\S$ Laboratory of Physical and Analytical Electrochemistry, EPFL Valais Wallis, Rue de l'Industrie 17, CP 440, CH- \\ 1951 Sion, Switzerland.
}

\begin{abstract}
Herein is reported a near-field microscopy based on electrochemiluminescence (ECL) which allows to image the plasma membrane of single cells at the interface with an electrode. By analyzing photoluminescence (PL), ECL and AFM images of mammalian CHO cells, we demonstrate that, in contrast to the wide-field fluorescence, ECL emission is confined to the immediate vicinity of the electrode surface and only the basal membrane of the cell becomes luminescent. The resulting ECL microscopy reveals details which are not resolved by classic fluorescence microscopy, without any light irradiation and specific setup. The thickness of the ECL-emitting regions is $\sim 500 \mathrm{~nm}$ due to the unique ECL mechanism which involves short-lifetime electrogenerated radicals. In addition, the reported ECL microscopy is a dynamic technique which reflects the transport properties through the cell membranes and not only the specific labeling of the membranes. Finally, disposable transparent carbon nanotube (CNT)-based electrodes inkjet-printed on classic microscope glass coverslips, were used to image cells in both reflection and transmission configurations. Therefore, our approach opens new avenues for ECL as a near-field microscopy to develop single cell assays and to image the dynamics of biological entities in cells or in membranes.
\end{abstract}

\section{Introduction.}

The cell membrane is an electrical and physical barrier integrating diverse and complex structures (e.g. proteins, phospholipids, sugars) where the cell interacts with the environment and responds to local biological or physicochemical variations. Imaging single cell membranes and detecting specific membrane protein biomarkers is mandatory for developing early diagnosis in medicine and for investigating fundamental issues in biology. ${ }^{1-5}$ For example, the selective measurement of overexpressed membrane proteins on tumor cells is critical for diagnosis and dedicated disease treatment. ${ }^{3,6-8}$ These proteins are of great interest, particularly because they constitute targets for antibodies in immunoassays and immunohistochemistry. The study of protein transport and trafficking is required to understand the function and organization of the cell. Imaging these processes at single cells with high spatiotemporal resolution is challenging but also rewarding and a large variety of optical and electrochemical techniques have been developed on this purpose.

Fluorescence microscopy, especially confocal laser fluorescence microscopy, total internal reflection fluorescence (TIRF) microscopy and single molecule microscopies, are widely used to image specific protein localizations and various functions like effector-receptor interactions, membrane fusion, channel activities, etc. ${ }^{2,4}$ However, autofluorescence of the sample (from flavins at least) is an intrinsic limitation of such techniques that can be avoided or minimized with methods based on other physical principles. For example, electrochemical methods based on micro/nanoelectrodes also provide high spatiotemporal resolution and excellent local sensitivity allowing to

This item was downloaded from IRIS Università di Bologna (https://cris.unibo.it/)

When citing, please refer to the published version. 
investigate complex biological processes at the single cell level such as the release of species during exocytosis or oxidative stress. $^{9-15}$ Scanning single cells with a microelectrode in SECM mode was reported for the study of cell respiration $^{16,17}$ and metabolic processes, ${ }^{18-20}$ molecular uptake, ${ }^{21}$ or morphological variations. ${ }^{15,22}$ In spite of many successful applications, the major limitation of SECM is its temporal resolution related to the requirement to scan the sample in order to reconstruct an image of the "electrochemical" activity or topography of the cells, even if arrays of soft microelectrodes constitute a promising approach. ${ }^{23-25} \mathrm{Zu}$ et al. reported a near-field scanning optical microscopy (NSOM) with an ECL light source produced at a nanoelectrode tip. ${ }^{26}$ This ECL nanoprobe was scanned over the substrates (typically, interdigitated electrode arrays and samples containing submicrometer holes) using the shear force mode. In this overall context, developing novel ultrasensitive imaging methods for the analysis of cellular and subcellular events ${ }^{27,28}$ is still a very active research area.

In order to broaden the strategies available for studying the topology or activities of cell membranes, we report here the design and application of a new class of near-field microscopy, which combines electrochemical and luminescence methodological principles. We propose to involve electrochemiluminescence (ECL) as a readout mechanism to image the plasma membrane including its passive transport properties. ECL is an electrochemically triggered process that leads in fine to photon emission. ${ }^{29,30}$ The excited state of the luminophore is reached by a homogeneous exergonic electron-transfer reaction between electrogenerated species. Then the excited luminophore relaxes to the ground state and emits light. Thus, ECL intimately combines orthogonal steps: electrochemistry and photochemistry, which govern the initiation and termination steps of the process, respectively. The electrochemical stimulation allows controlling very precisely the location and the duration of the ECL-emitting region whereas the optical readout makes the method extremely sensitive. In addition, ECL has the advantage of not requiring an excitation light source unlike photoluminescence (PL) techniques (i.e. fluorescence or phosphorescence). It results in an extremely low background, high sensitivity detection and a simple instrumentation that can be coupled to microscopy. ${ }^{31}$ By exploiting these remarkable characteristics, clinical ECL-based analyzers are commercialized for a large number of immunoassays, such as for cardiac and infectious diseases, thyroid and tumor markers, etc. ${ }^{32-34}$ Model systems providing high ECL efficiency in biological fluids (e.g. urine or serum) consist of a ruthenium polypyridine luminophore, $\left[\mathrm{Ru}(\mathrm{bpy})_{3}\right]^{2+}$, with tripropylamine (TPA) as a sacrificial coreactant species. This latter is oxidized at the electrode surface and generates highly-reactive radicals that diffuse over short distances and react with $\left[\mathrm{Ru}(\mathrm{bpy})_{3}\right]^{2+}$ to produce its excited state. Therefore, depending on the chemical stability of the radicals, ECL emission occurs in the coreactant reaction layer at the vicinity of the electrode surface..$^{35-37}$

For imaging applications, ECL was used previously to visualize single entities such as nanowires, ${ }^{27}$ beads for immunoassays, ${ }^{36,38,39}$ collisions of attoliter droplets, ${ }^{28}$ graphene oxide nanoparticles, ${ }^{40}$ and Janus metallic nanoparticles ${ }^{41}$. At the single cell level, effluxes of hydrogen peroxide were observed with luminol ECL. ${ }^{42-45}$ Recently, $^{2}$ we reported the ECL imaging of single cells exploiting the reactivity of the tandem $\left[\mathrm{Ru}(\mathrm{bpy})_{3}\right]^{2+} / \mathrm{TPA}$ system. ${ }^{46}$ However, since the plasma membrane was not permeable to the coreactant, only the cell borders were observed and the rest of the plasma membrane (i.e. central regions of the cells) remained dark. It is a major constraint, which limits drastically the development of ECL for cell imaging. On the other hand, when considering that ECL is based on an initial electrochemical reaction occurring directly at the electrode surface, it has the potential to offer not only the imaging of labeled cell components but also to study their structural dynamics by giving access to transport properties through the membranes. Investigating original strategies to overcome this biological barrier due to the initial electrochemical step and the hindered diffusion of the coreactant is therefore of paramount importance to expand ECL abilities at the level of cells, for example, in ultrasensitive single cell imaging assays. ${ }^{47-49}$ In addition, the spatial characteristics of such an ECL-based near-field microscopy with enhanced vertical resolution have never been reported, even more for the imaging of cells and their plasmic membranes.

Herein, we show the efficient generation of ECL at the level of the entire basal membrane of single cells (Scheme 1). In contrast to the classic wide-field fluorescence microscopy, we demonstrate that the ECL emission is confined to the immediate vicinity of the electrode surface and generated only at the level of the basal membrane. The limited extension of the ECL-emitting region, comparable to the ECL wavelength but much smaller than the thickness of a diffusion field, is defined by the short lifetimes of the electrogenerated TPA radicals. Conceptually, this feature of ECL is reminiscent of TIRF microscopy where the optical signal is restricted within a few hundred nanometers from the surface. Finally, cell membranes were imaged by ECL microscopy in reflection configuration on GC electrodes as well as in transmission configuration (Scheme 1a) with disposable transparent CNT-based electrodes that were inkjetprinted on classic glass coverslips. Therefore, our wide-field approach expands the applicability of ECL to diverse optical microscopies by imaging biological entities with near-field features.

This item was downloaded from IRIS Università di Bologna (https://cris.unibo.it/)

When citing, please refer to the published version. 

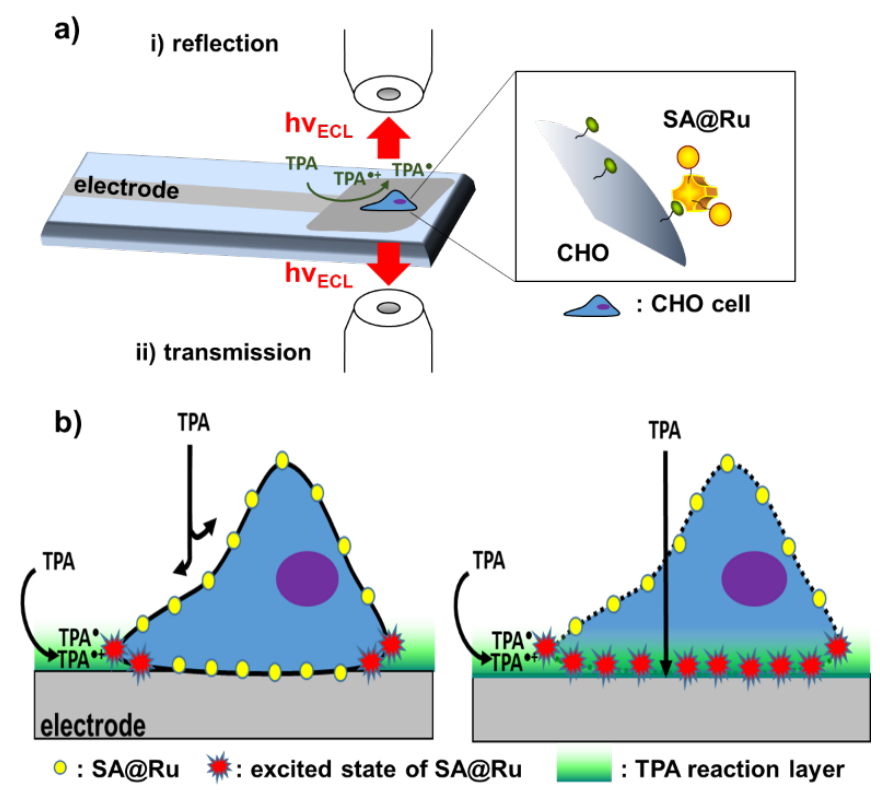

Scheme 1. Schematic principle of the near-field ECL microscopy of labeled cells (i) in reflection configuration with the GC electrode or (ii) in transmission configuration through the transparent CNT inkjet-printed electrodes. a) SA@Ru labels were attached to the biotinylated proteins of the cellular membrane. b) Influence of the membrane permeabilization step on the ECL responses of (left) fixed and (right) permeabilized cells. It illustrates the effects of the permeabilization step on the TPA diffusion through the cell membrane and on the resulting localization of the ECL-emitting regions.

\section{Experimental section.}

Materials. Tripropylamine (TPA), 2-(dibutylamino) ethanol (DBAE), phospate buffered saline (PBS) solution (pH 7.4), streptavidin from Streptomyces avidinii, bis(2',2-bipyridine)-4'-methyl-4-carboxybipyridine-ruthenium Nsuccinimidyl ester-bis(hexafluorophosphate) $\left[\mathrm{Ru}(\mathrm{bpy})_{2}\left(\mathrm{mcbpy}-\mathrm{O}-\mathrm{Su}\right.\right.$-ester) $\left.\left(\mathrm{PF}_{6}\right)_{2}\right]$ and paraformaldehyde (PFA) were from Sigma-Aldrich and used without any further purification. Triton X-1oo was from Acros Organic. Iscove's modified Dulbecco's medium, fetal bovine serum, PBSix, trypsin and penicillin / streptomycin $100 \mathrm{U} / \mathrm{mL}$ were from Gibco. Biotin X was from Fisher Scientific. DMSO was from Invitrogen. Phosphate buffer solution (PBS) o.1 M (pH = 7.4) was obtained by mixing o.1 $\mathrm{M}$ of sodium phosphate monobasic monohydrate $\left(\mathrm{NaH}_{2} \mathrm{PO}_{4} \cdot \mathrm{H}_{2} \mathrm{O}\right)$ and o.1 M sodium phosphate dibasic heptahydrate $\left(\mathrm{Na}_{2} \mathrm{HPO}_{4} \cdot 7 \mathrm{H}_{2} \mathrm{O}\right)$, both from Sigma-Aldrich and used as received.

Cell culture, labeling and permeabilization. CHO-Ki cells were from Public Health England (HPA) Culture Collections and supplied by Sigma (85051005). Iscove's modified Dulbecco's medium (IMDM) supplemented with 10 $\%$ fetal bovine serum and penicillin/ streptomycin $100 \mathrm{U} / \mathrm{mL}$ were used to grow cells in an incubator. CHO-Kı cells were trypsinized, plated on glassy carbon electrode or in a Petri dish containing CNT electrode and incubated $48 \mathrm{~h}$ with culture medium at $37^{\circ} \mathrm{C}, 5 \% \mathrm{CO}_{2}$. A solution of $100 \mu \mathrm{L}$ of ruthenium complex (10 mg/ mL) in anhydrous DMSO, $100 \mu \mathrm{L}$ of streptavidin $\left(1 \mathrm{mg} / \mathrm{mL}\right.$ in PBS), and 8oo $\mu \mathrm{L}$ PBS was prepared. The solution was vortexed for $4 \mathrm{~h}$ at $4{ }^{\circ} \mathrm{C}$ and dialyzed overnight under stirring at $4{ }^{\circ} \mathrm{C}$. Before ECL experiment, CHO-Kı cells were fixed 10 min with PFA $4 \%$, permeabilized 10 min with Triton X-10o $0.1 \%$, labeled with biotin $\mathrm{X} 11 \mu \mathrm{M}$ and streptavidin-ruthenium complex solution SA@Ru (o.1 mg/mL).

Instrumentation. The ECL/PL microscopies were performed in a PTFE (Teflon) homemade electrochemical cell. The ECL imaging cell was used in a three-electrode configuration, in which glassy carbon or CNT electrode acted as working electrode, $\mathrm{Ag} / \mathrm{AgCl}(\mathrm{KCl}, 3 \mathrm{M})$ as reference electrode and a Pt wire as counter electrode. For ECL experiments, the potential applied to the working electrode was $1.4 \mathrm{~V}$ vs. $\mathrm{Ag} / \mathrm{AgCl}\left(\mathrm{KCl},{ }_{3} \mathrm{M}\right)$. For microscopic imaging, an epifluorescence microscope from Leica (DMI6000, Leica Microsystems) equipped with ultrasensitive ElectronMultiplying Charge Coupled Device camera (EM-CCD 9100-13 from Hamamatsu, Hamamatsu Japan) was used with an inverted $63 \mathrm{x}$ microscope objective from Leica $(63 \mathrm{x} / 1.2,0.2 \mathrm{~mm})$. The integrated system also included a potentiostat from AUTOLAB ( $\mu$ AUTOLAB, type II) suitable to provide the required potential to generate ECL.

Atomic Force Microscopy. AFM experiments were performed with a Veeco MultiMode 8.

This item was downloaded from IRIS Università di Bologna (https://cris.unibo.it/)

\section{When citing, please refer to the published version.}


Fabrication and characterization of the inkjet-printed CNT electrodes. The CNT electrodes were fabricated first on polyethylene terephthalate sheets (PET, $125 \mu \mathrm{m}$ thick) and then on glass microscope coverslips (VWR, 631-1573, 0.13$0.16 \mathrm{~mm}$ thickness) following our previously established inkjet-printing protocols ${ }^{50}$ and by using an X-Serie CeraPrinter (Ceradrop) with piezoelectric Dimatix Q-class Sapphire QS-256-8opL print-heads and disposable DMC-11610 cartridges. The Ceraprinter was combined with a PulseForge 1300 photonic curing system (Novacentrix) and a FireEdge FE300 380-420nm UV LED (Phoseon Technology) for rapid flash light-induced thermal and photochemical postprocessing, respectively. In brief, Jettable nano silver Silverjet DGP-40LT-15C (w/w 30-35\%, Sigma Al-drich) was printed and photonic cured as electrical connection layer. The CNT dispersion BSI.B16171_A (Brewer Science) was printed and photonic cured to generate the transparent CNT working electrode and the jettable insulator EMD6201 (Sun Chemical) was printed and quasi-simultaneously polymerized as insulation layer. For each printing process, essential printing parameters, such as piezoelectric actuation, jetting frequency, etc. were optimized and after printing all layers the electrodes were ready to use. The transmittance of a $1 \mathrm{~cm}^{2}$ CNT layer on glass was measured with an 8453 UV-visible spectroscopy system (Agilent Technologies). The inkjet-printed CNT pattern was characterized using a Fei Teneo scanning electron microscope (SEM).

\section{Results and discussions.}

To develop ECL microscopy of cell membranes, mammalian Chinese Hamster Ovary (CHO) cells were grown first on glassy carbon (GC) electrodes. These adherent cells were fixed and then labeled with a prototypical ECL agent, i.e. $\left[\mathrm{Ru}(\mathrm{bpy})_{3}\right]^{2+}$, using the biotin-streptavidin interactions (Scheme 1a). Biotinylation of the membranes was performed by incubating the cells with biotin $\mathrm{X}$, which reacts with primary amino groups of cell surface proteins. Such biotinylation method is classically used in biology to label specifically extracellular proteins of the membrane, whereas intracellular proteins remain unlabeled. Streptavidin-modified $\left[\mathrm{Ru}(\mathrm{bpy})_{3}\right]^{2+}$ labels (noted SA@Ru or SA@ $\left[\mathbf{R u}(\mathbf{b p y})_{3}\right]^{2+}$ ) were then attached to the biotinylated proteins of the cellular membrane. ${ }^{51}$ The PL signal reflects the sites of the immobilized ruthenium labels on the plasma membrane and the PL image (Figure 1) shows that the whole plasma membrane was labeled by SA@Ru. When applying $1.4 \mathrm{~V}$ to the GC electrode in presence of TPA, the SA@Ru labels react with the electrogenerated TPA radical species. We selected this potential value because it leads to strong and stable ECL signals on labeled cells (Figure $\mathrm{S}_{1}$ ). In this first series of experiments, cells were fixed without further modification (Figure 1a). ECL spatial distribution recorded in reflection configuration (Scheme 1a) reveals that light emission is restricted to the external cell borders. ${ }^{46}$ It is also clearly visible on the right part of Figure 1a where 4 cells are in close contact and only their periphery is ECL-active. This is due to the hindered diffusion of TPA through the plasma membrane, from the cell upper part or from sides at its basis, toward the electrode surface (Scheme $1 b$, left). Therefore, TPA cannot be oxidized at the electrode surface in the central part of the cell and these regions remain dark. Only the cell borders close to the electrode surface are exposed to the concentration gradients of TPA radicals (i.e. TPA reaction layer $)^{36,46}$ and local SA@Ru labels emit ECL light. As a result, the localization of the ECL-emitting regions depends not only on the labeling step but also on the transport properties of the coreactant species near or through the membrane.

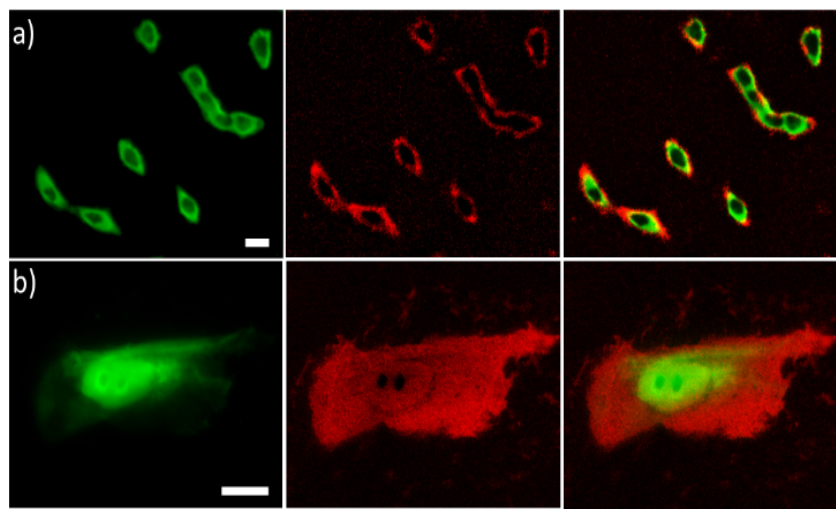

Figure 1. PL (green), ECL (red) and overlay of both luminescence signals (from left to right) of CHO cells that were (a) labeled with SA@Ru or (b) permeabilized and then labeled with SA@Ru. Cells were grown on GC electrodes. SA@Ru labels were attached to the biotinylated proteins of the cellular membrane. Both PL and ECL images were recorded in the reflection configuration on the same regions of interest in the ECL focal plane. ECL was generated in PBS $(\mathrm{pH}=7.4)$ containing 100 mM TPA by applying $1.4 \mathrm{~V}$. Scale bar: $20 \mu \mathrm{m}$.

This item was downloaded from IRIS Università di Bologna (https://cris.unibo.it/)

When citing, please refer to the published version. 
To push further the imaging abilities offered by ECL at cell membranes, it was essential to overcome this important limitation due to the cell barrier. For that, we applied a standard biological procedure used to permeabilize lipid bilayers and cell membranes. The cells were thus incubated with Triton X-10o as classically performed in immunofluorescence or Western blot techniques. ${ }^{2,53}$ Triton X-10o, a nonionic surfactant, is widely exploited to permeabilize the cell membranes, including the nuclear membrane, for DNA transfection or further labeling steps. Indeed, permeabilization provides access to intracellular or organelle proteins. Thus, Figure $1 \mathrm{~b}$ shows the compared PL and ECL images of a single cell after incubation with Triton X-10o. One can clearly observe that ECL emission occurs now at the whole cell membrane facing the electrode (Figure $1 b$ ), and not only from the cell borders (Figure 1a). Such a significant result proves unambiguously that TPA diffusion through the membranes, at least through the plasma membrane, is essential for a global imaging of the cell (Scheme ib, right). Moreover, ECL light is also detected in the nucleus region, which illustrates that even the nucleus membrane has become permeable to TPA following this procedure. A detailed observation of both PL and ECL images (Figure $1 \mathrm{~b}$ ) shows that 2 nucleoli are present in the nucleus. However, they remain dark because they have not been permeabilized and they block the TPA diffusion from the bulk to the electrode surface. Thus, diffusion of TPA through the membranes governs the location of the ECLemitting regions within the cell as well as the proximity to the electrode surface. Consequently, such ECL microscopy does not reflect only the spatial distribution of the labels and the structure of the plasma membrane but reveals also the passive transport properties through the membranes. Therefore, our approach may allow investigating the transport and trafficking across the cell membranes.

DBAE is an environmentally friendly co-reactant, which gives stronger ECL intensity than TPA when the $\left[\mathrm{Ru}(\mathrm{bpy})_{3}\right]^{2+}$ luminophores are free in solution (not immobilized as in the present case on cells). ${ }^{54}$ We tested its performance on the SA@Ru labelled cells (Figure S2). But we have not been able to record any ECL image of the cells using DBAE. The ECL intensity was below the detection limit. In a previous work, ${ }^{36}$ ECL emission was also extremely low at the level of SA@Ru-modified beads. Such a behavior might be attributed to the intervention of a very unstable intermediate and/or to the inadequate potential of the DBAE $^{\bullet+}$ radical, which is unable to populate the excited state by reaction with SA@ $\left[\mathbf{R u}(\mathbf{b p y})_{3}\right]^{+}$(reaction 4$)$.

To demonstrate the near-field feature and the vertical resolution of the presented ECL-based microscopy, we analyzed and compared both PL and ECL images in different focal planes (Figure 2). When considering resolution in optical microscopy, in addition to the lateral resolution, the main characteristic is the vertical resolution. ${ }^{55,56}$ For instance, in wide-field fluorescence microscopy, the excitation wavelength provokes the entire object to fluoresce and, in usual conditions, more than $90 \%$ of the collected fluorescence signal is out-of-focus emission. that can completely mask the in-focus details. ${ }^{55}$ Vertical resolution is determined by the depth of field so that a thin section of the cell can be imaged..$^{55,56}$ The depth of field may be defined as the distance from the nearest object plane in focus to that of the farthest plane also simultaneously in focus. ${ }^{57}$

Figure 2 shows PL and ECL images of the same region of interest presenting 2 adherent cells on the GC electrode. These images have been recorded in the reflection configuration (Scheme 1a) with a high numerical aperture (1.2) 63x objective in different focal planes. The depth of field of the objective is $400 \mathrm{~nm}$. By adjusting the focus in the PL mode (Figure 2a), the cell and nucleus membranes are clearly imaged as well as the pseudopods, which adhere to the electrode surface. The excitation source was then turned off and the ECL image recorded while applying a sufficiently positive potential to the GC electrode in presence of TPA. In this PL focal plane, the resulting ECL image appeared blurry, out-of-focus (Figure $\mathrm{S}_{3}$ ).

This item was downloaded from IRIS Università di Bologna (https://cris.unibo.it/)

When citing, please refer to the published version. 

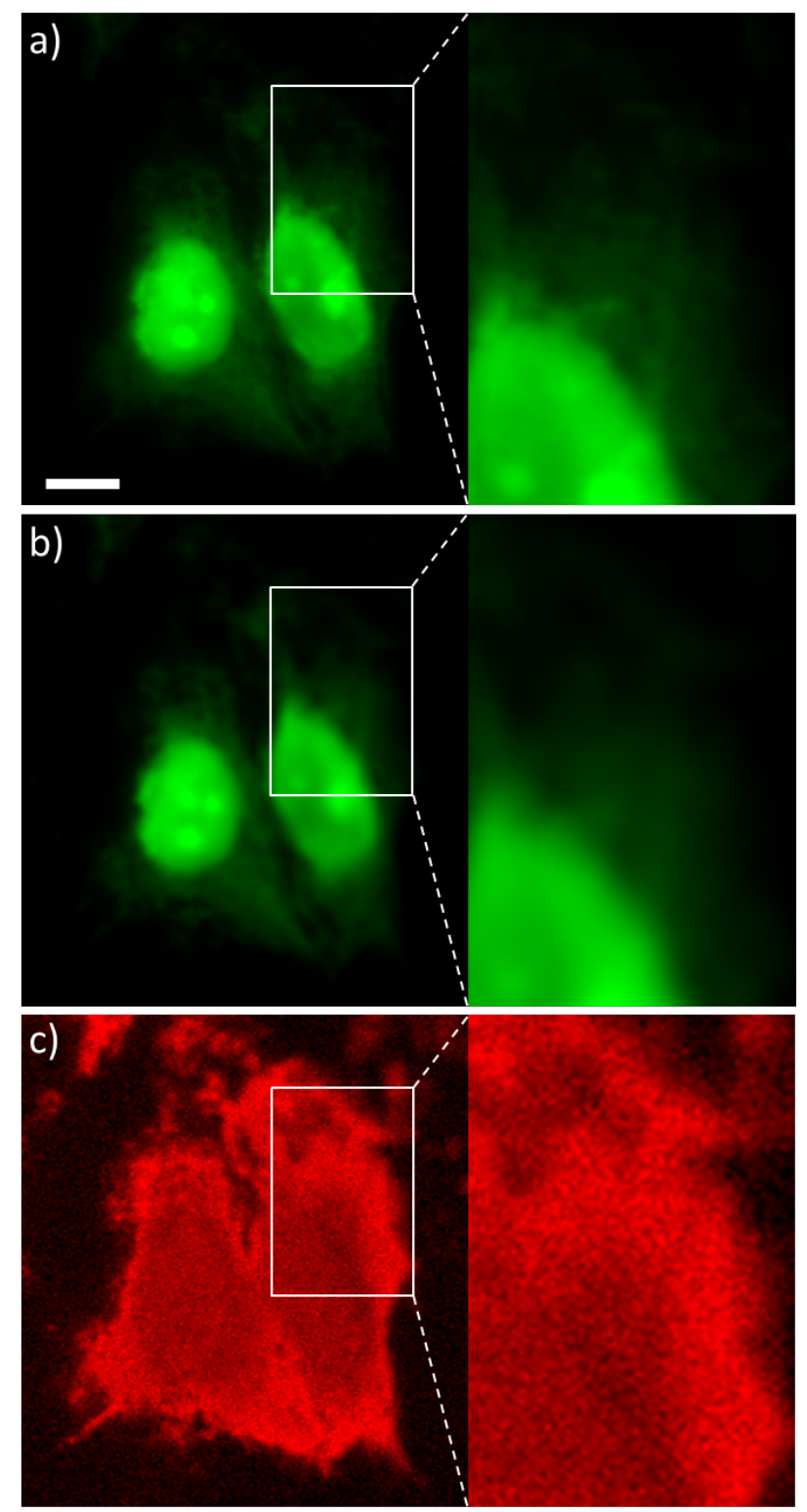

Figure 2. PL images of the same CHO cells focused in the focal (a) PL or (b) ECL planes at different magnifications. (c) ECL images of the same region of interest recorded with the objective focused in the focal ECL plane (i.e. similar to b). Cells were grown on GC electrodes and then treated with Triton X-10o for 10 min. SA@Ru labels were attached to the biotinylated proteins of the cellular membrane. Both PL and ECL images were recorded in the reflection configuration. ECL was generated in PBS $(\mathrm{pH}=7.4)$ containing $100 \mathrm{mM}$ TPA. Scale bar: $10 \mu \mathrm{m}$.

Well-defined ECL imaging of the cell (Figure 2c), actually of its plasma membrane, was obtained when moving the focal plane of the objective $1.2 \mu \mathrm{m}$ below the previous PL focus, i.e. closer to the electrode surface. If we recorded the PL image in this adequate focal plane for ECL, PL image of the cells appeared blurry, not well-defined (Figures $2 \mathrm{~b}$ and S4). It means that the focal PL and ECL planes are distinct and not located at the same distance from the electrode surface. The mean average distance between PL and ECL focal planes has been evaluated as $1.2 \pm 0.4 \mu \mathrm{m}(\mathrm{n} \geq 30 \mathrm{CHO}$ cells). In other words, the ECL focal plane is located $1.2 \pm 0.4 \mu \mathrm{m}$ closer to the electrode surface in comparison to the PL focal plane. This conclusion appears fully logic since PL is acquired in far-field mode and provides a whole cell image of all SA@Ru labels present on membranes from the apical (top) to the basal (down) planes of the cell. Otherwise, ECL emission only occurs from SA@Ru labels reacting with TPA electrogenerated radicals, meaning in the TPA reaction layer (Scheme $\mathrm{ib}$ ) between the electrode surface and basal cell membranes.

This item was downloaded from IRIS Università di Bologna (https://cris.unibo.it/)

When citing, please refer to the published version. 

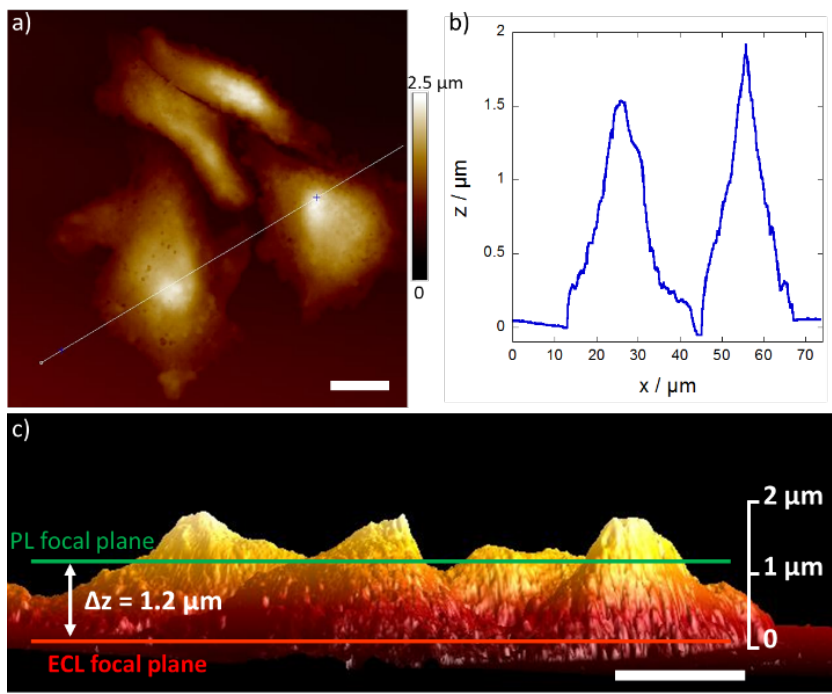

Figure 3. (a) Top and (c) side views of AFM images of CHO cells grown on a GC surface. The bright regions correspond to the nuclei region. (b) Cross-section profile of two adjacent cells along the white line materialized on Fig. 3a. On the side view, both mean PL (green) and ECL (red) focal planes are schematically represented. Scale bars: $10 \mu \mathrm{m}$.

In order to characterize better the topology and thickness of $\mathrm{CHO}$ cells, we performed AFM analyses on CHO cells ( $\sim 70 \%$ confluent) grown on a GC surface (Figure $3 \mathrm{a})$. Typical dimensions of the cells were about $30-70 \mu \mathrm{m}$ in diameter, similarly to when observed in usual culture conditions. On the AFM images, characteristic brighter regions corresponding to higher parts in the central region of the cells (Figure 3a) are attributed to the nucleus areas. The zones surrounding the nuclei correspond to the cytoplasm, which becomes progressively thinner at the pseudopods ensuring the adhesion on the surface. Typical profiles for two cells are represented on Figure $3 \mathrm{~b}$. Nuclei regions appeared about 1.5-2 $\mu \mathrm{m}$ in height whereas cell borders are about $1 \mu \mathrm{m}$. These AFM results are in good agreement with similar topographic studies also performed on $\mathrm{CHO}$ cells. ${ }^{58}$ Considering the cell morphology and thickness, the PL focal plane is located in the middle of the cell, as schematized on Figure 3c. Since the ECL focal plane is $1.2 \pm 0.4 \mu \mathrm{m}$ below the PL focal plane, ECL is truly emitted from a cell zone in the immediate vicinity of electrode surface, i.e. in the TPA reaction layer (Scheme ib). In other words, ECL emission is confined to the basal cell membrane (Figure 3c).

The plasma membrane is usually separated from the substrate (i.e. in our case, the electrode surface) by $\sim 100-150$ $\mathrm{nm}$ via the formation of extracellular matrices-integrin-cytoskeleton linkages, as demonstrated by TIRF and SPR microscopies. ${ }^{59,60}$ Therefore, since the cell membrane has been biotinylated and labeled with the SA@Ru, ECL emission is intrinsically confined next to the electrode surface and it arises from the basal cell membrane. Consequently, such ECL imaging offers a near-field vertical resolution of biological structures at distances below the emission wavelength of the ruthenium fluorophore $(615 \mathrm{~nm})$. This is emphasized by the comparison of PL and ECL images (Figures 2a and 2c), which shows also that ECL allows the imaging of a significantly larger spatial extension of the cell borders. The parts of the plasma membrane that reside closer to the electrode surface produce stronger ECL and they are revealed by ECL microscopy whereas they remain dark with PL. The contrast is indeed much improved in comparison to PL images. This means that different but complementary information are provided by classic fluorescence microscopy and the ECL-based microscopy. Conceptually, the limited extension of the probed space is equivalent to TIRF microscopy, which is an optical technique confined to the observation interface, due to the nonpropagating properties of the evanescent electromagnetic field. Indeed, the evanescent wave decays exponentially into the sample within few hundreds of nanometers, typically $\sim 300 \mathrm{~nm}$ from the surface. Thus, only the fluorophores located in this space are photo-excited and may contribute to the fluorescence signal.

For the ECL microscopy, the limited extension of the ECL-emitting region results from the unique mechanism of TPA coreactant with SA@Ru labels. ${ }^{35,36}$ TPA was selected as a sacrificial "oxidative-reduction" coreactant because it can "electro-excite" the ECL labels at a submicrometric distance from the electrode surface, by reaction of immobilized SA@Ru with the diffusing electrogenerated TPA radicals (Scheme 1b). As demonstrated in bead-based immunoassays, the resulting heterogeneous ECL emission has been rationalized considering the following reaction mechanism: ${ }^{35}$

This item was downloaded from IRIS Università di Bologna (https://cris.unibo.it/)

When citing, please refer to the published version. 


$$
\begin{aligned}
& \mathrm{TPA}-\mathrm{e} \leftrightarrows \mathrm{TPA}^{\bullet+} \\
& \mathrm{TPA}^{\bullet+} \leftrightarrows \mathrm{TPA}^{\bullet}+\mathrm{H}^{+} \\
& \mathrm{TPA}^{\bullet}+\mathrm{SA} @\left[\mathrm{Ru}(\mathrm{bpy})_{3}\right]^{2+} \leftrightarrows \mathrm{P}+\mathrm{SA} @\left[\mathrm{Ru}(\mathrm{bPy})_{3}\right]^{+} \\
& \mathrm{TPA}^{\bullet+}+\mathrm{SA} @\left[\mathrm{Ru}(\mathrm{bpy})_{3}\right]^{+} \leftrightarrows \mathrm{TPA}+\mathrm{SA} @\left[\mathrm{Ru}(\mathrm{bPy})_{3}\right]^{2+*} \\
& \mathrm{SA} @\left[\mathrm{Ru}(\mathrm{bPy})_{3}\right]^{2+*} \rightarrow \mathrm{SA} @\left[\mathrm{Ru}(\mathrm{bPy})_{3}\right]^{2+}+\mathrm{h} v_{\mathrm{ECL}}
\end{aligned}
$$

where $\mathrm{P}$ is the product of the homogeneous $\mathrm{TPA}^{\bullet}$ oxidation.

Since the SA@Ru labels are immobilized on the plasma membrane, the luminophores might not be oxidized directly at the electrode surface in this mechanistic pathway. We checked this point by recording differential pulse voltammograms of the GC electrodes on which $\mathrm{CHO}$ cells were grown and we have not observed any measurable current at the oxidation potential of the ruthenium complex (Figure $\mathrm{S}_{5}$ ). In the present scheme, only TPA is oxidized at the electrode (reaction 1 ) and it generates the cation radical TPA ${ }^{\bullet+}$, which deprotonates rapidly to form the strong reducing neutral radical TPA ${ }^{\bullet}$ (reaction 2). This latter reduces $\mathbf{S A @}\left[\mathbf{R u}(\mathbf{b p y})_{3}\right]^{2+}$ to $\mathbf{S A @}\left[\mathbf{R u}(\mathbf{b p y})_{3}\right]^{+}($reaction 3$)$. Then TPA $^{\bullet+}$ oxidizes SA@ $\left[\mathbf{R u}(\mathbf{b p y})_{3}\right]^{+}$to populate the excited state of the label (reaction 4 ). Finally, it deactivates to the ground state and emits a photon (reaction 5). In the present mechanism, ECL generation requires only the TPA oxidation at the electrode surface to produce simultaneously both TPA radicals at the same location (i.e. TPA reaction layer) and to form the excited state of SA@Ru. In the reaction scheme 1-5, the key kinetic parameter is the rate constant for the deprotonation of the TPA ${ }^{\bullet+}$ radical, leading to a half-life time of $\sim 0.24 \mathrm{~ms}^{35,36}$ Taking into account the overall mechanistic scheme for TPA (reactions 1-5), simulations in bulk configuration have shown that maximum ECL intensity occurs at $0.5 \mu \mathrm{m}$ from the electrode surface and then decays exponentially until $1 \mu \mathrm{m} .{ }^{35,36,46}$ The extension of this ECL layer might even be smaller within or in the cell-electrode interspace in comparison to the bulk situation. Therefore, this finite ECL reaction layer, which results from the reactivity of the TPA radicals, provides the near-field vertical feature for generation and observation of ECL luminophores. In other words, TPA reactivity limits the light emission over the basal region of the cell membrane.SA@Ru labels located further, i.e. on the apical cell membrane, are not electrochemically excited by the TPA radicals and do not contribute to the ECL signal. The submicrometric extension of the ECL reaction layer, where the labels are excited by a cascade of redox reactions, is conceptually similar to the evanescent wave in TIRF microscopy, which photo-excites the luminophores. Finally, since the thickness of this "evanescent" ECL reaction layer depends on the lifetimes of the cation coreactant radicals, we envision that its extension could be modulated, i.e. increased or reduced by using other coreactants possessing different lifetimes of the electrogenerated radicals. Therefore, various heights and regions of the substrates or cells could be imaged by ECL microscopy by adapting this strategy.

The last part of this work was devoted to widen the applicability of the above ECL microscopy by using innovative electrode supports. In the experiments above, we used first GC as the electrode surface because carbon-based materials give strong ECL signals due to their efficient TPA oxidation and a low fouling by biomolecules. ${ }^{61}$ However, since GC is opaque, ECL microscopy on such electrode is limited to the reflection configuration (Schema 1a). In addition, GC materials cannot be used routinely for traditional optical microscopies since it requires several preparations steps (cleaning, polishing). Ideal electrode materials for ECL microscopy should associate high electrical conductivity, excellent electrochemical stability and high optical transparency. Transparent metal oxide electrodes, such as indiumdoped tin oxide (ITO) and fluorine-doped tin oxide (FTO), are currently the standard materials for transparent electrodes. ${ }^{61}$ But the rather limited stability of these oxides restricts the electrochemical potential window and their low efficiency for TPA oxidation leads to very low ECL intensity compared to carbon-based materials.

This item was downloaded from IRIS Università di Bologna (https://cris.unibo.it/)

When citing, please refer to the published version. 

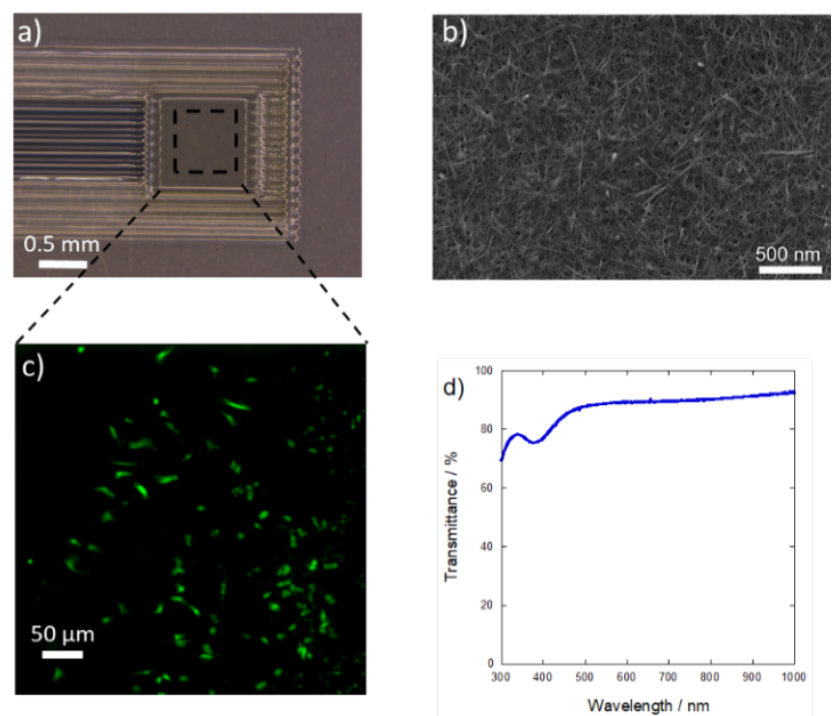

Figure 4. (a) Photograph of the inkjet-printed CNT electrodes on the microscope glass coverslips. b) SEM of the CNT electrode surface. c) PL images of the CHO cells grown on the inkjet-printed CNT electrodes. d) Transmission curve of the inkjet-printed CNT electrodes.

To extend our ECL-based approach to the transmission configuration and to develop more practical disposable devices for microscopy, CNT-based transparent electrodes were fabricated by inkjet-printing first on polyethylene terephthalate sheets and then on microscope glass coverslips (Figure S6). This inkjet-printing technology approaches progressively the industrial production level at reasonable costs for thin layer materials. In the transmission PL configuration, the PET layer induces some optical distortions probably related to the different refractive index of PET (Figure $\mathrm{S}_{7}$ ). Then we used classic microscope glass coverslips (o.13-0.16 mm thickness) on which the CNT layers were printed (Figure 4). Such glass coverslips are ideal for biologists and for researchers working with microscopy because it is a standard object in their field. An inkjet-printed silver Ag pattern served as electrical connection for the printed CNT layer just by minor overlapping these two layers (Figure S6). The heart of the printed electrode is a stand-alone CNT layer on the glass coverslip ("CNT/glass", Figure 4a). An inkjet-printed insulation layer ("Insu/CNT/glass") defined precisely the stand-alone CNT working electrode area and protected the Ag from the solution ("Insu/Ag/glass"). The SEM image shows a uniform surface coverage of the glass substrate by the CNT (Figure $4 \mathrm{~b}$ ). The oxidation of TPA occurs efficiently on such CNT electrode surfaces and their electrochemical performances are indeed comparable to GC electrodes giving an ECL emission ten times higher compared with standard transparent ITO electrode. ${ }^{39}$ The CNT-printed electrodes were quasi-transparent allowing $\sim 90 \%$ of transmission (Figure $4 \mathrm{~d}$ ) at the emission wavelength of $\left[\mathrm{Ru}(\text { bpy })_{3}\right]^{2+}$ (i.e. $615 \mathrm{~nm}$ ). Further, $\mathrm{CHO}$ cells were cultured on the inkjet-printed CNT electrodes as illustrated by the PL image (Figure 4c). Cell viability on the CNT layer was comparable to a glass substrate, as reported previously. ${ }^{46}$

Figure 5a shows the PL image of the CHO cells in the transmission configuration through the CNT layer (Schema 1a). Cells appeared relatively separated when observed in the PL mode. Then, we imaged the same region of interest in ECL with the transmission configuration (Figure $5 \mathrm{~b}$ ). ECL light is generated at the level of the basal cell membrane (vide supra), transmitted through the CNT layer and the coverslip, and collected by the microscope objective (Scheme 1a).
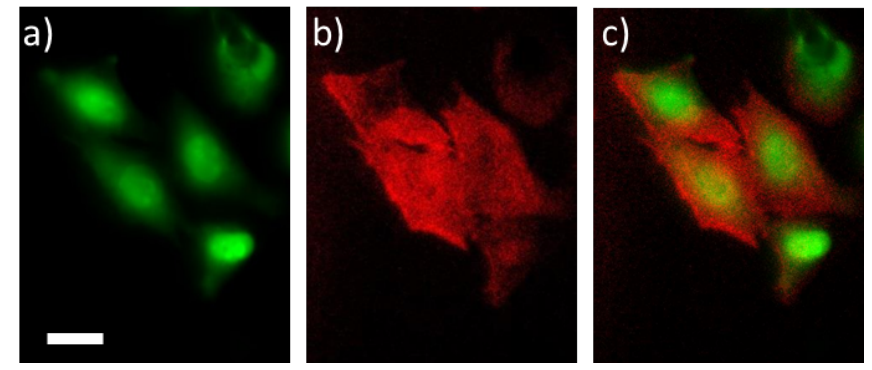

This item was downloaded from IRIS Università di Bologna (https://cris.unibo.it/)

When citing, please refer to the published version. 
Figure 5. PL (a), ECL (b) and overlay of both luminescence images (c) of CHO cells that were obtained in the transmission configuration through the CNT inkjet-printed electrode. Cells adherently grown on the CNT electrodes were permeabilized and labeled with SA@Ru. ECL was generated in PBS ( $\mathrm{pH}=7.4)$ containing $100 \mathrm{mM}$ TPA. PL and ECL images were both recorded in the ECL focal plane. Scale bar: $20 \mu \mathrm{m}$.

The cells were previously permeabilized and one can observe the entire cell area by ECL microscopy. As a result, they appear much closer than in PL (Figure $5 \mathrm{c}$ ), similarly to images recorded in the reflection configuration with GC electrodes. As already discussed above, ECL allows the observation of a larger fraction of the plasma membrane with CNT-electrodes, in comparison to PL, because ECL is a surface-confined imaging technique. The regions of the labeled membrane located in the immediate vicinity of the electrode surface are clearly visible in ECL whereas they are not distinguished in PL. ECL microscopy allows observing membrane details, which are difficult to resolve by classic PL microscopy.

\section{Conclusions.}

In this work, we developed a near field-type microscopy based on ECL to image plasma membranes at the single cell level. By comparing PL, ECL and AFM images of the cells, we have demonstrated that, in contrast to classic fluorescence microscopy, the ECL emission is confined to the immediate vicinity of the electrode surface. Thus, only the basal membrane generates ECL light and ECL microscopy reveals details, which are hardly resolved by classic farfield fluorescence microscopy. The limited extension of the ECL-emitting region results from the ECL mechanism and the short lifetimes of the coreactant radicals. Conceptually, this subwavelength vertical resolution is reminiscent of TIRF microscopy with a restricted propagation depth of the evanescent wave. By using other coreactants presenting different radical lifetimes, we envision that the extension of the ECL-emitting regions can be modulated allowing to image different heights in substrates or in cells by ECL. Since ECL emission requires the oxidation of the coreactant at the electrode surface, the reported ECL microscopy is a dynamic technique. It does not visualize only the plasma membrane structures but it reflects also their passive transport properties. The presented strategy may allow investigating the transport and trafficking properties through the cell membranes. Finally, ECL microscopy is performed for the first time in both reflection and transmission configurations owing to disposable transparent CNTbased electrodes inkjet-printed on standard glass coverslips for microscopy. Therefore, our approach using such standard biological objects expands the possibilities of ECL to diverse microscopy fields by imaging globally the dynamics of biological entities. The presented near-field ECL microscopy offers exciting opportunities to study the dynamic properties of the cell membranes and promising applications in ultrasensitive cell imaging assays.

\section{ASSOCIATED CONTENT}

Supporting Information. ECL-potential curves. PL images of the CHO cells recorded at high magnifications in different focal planes. ECL microscopy with DBAE. DPV. Scheme and photograph of the inkjet-printed CNT electrodes on glass coverslips. Optical effects on the PET and glass coverslips.

\section{AUTHOR INFORMATION}

\section{Corresponding Author \\ * Neso.Sojic@enscbp.fr \\ ORCID \\ Neso Sojic: oooo-0oo1-5144-1015}

\section{Author Contributions}

The manuscript was written through contributions of all authors.

\section{Notes}

The authors declare no competing financial interest.

\section{ACKNOWLEDGMENT}

We thank Bordeaux INP and the Agence Nationale de la Recherche (MOLY, ANR-15-CE19-0oo5-02; NEOCASTIP ANR-15CEo9-0015-03) for their financial supports.

This item was downloaded from IRIS Università di Bologna (https://cris.unibo.it/) 


\section{REFERENCES}

(1) von Erlach, T. C.; Bertazzo, S.; Wozniak, M. A.; Horejs, C.-M.; Maynard, S. A.; Attwood, S.; Robinson, B. K.; Autefage, H.; Kallepitis, C.; del Río Hernández, A.; Chen, C. S.; Goldoni, S.; Stevens, M. M. Nat. Mater. 2018, 17, 237.

(2) Zheng, X. T.; Li, C. M. Chem. Soc. Rev. 2012, 41, 2061.

(3) Wu, L.; Qu, X. Chem. Soc. Rev. 2015, 44, 2963.

(4) Stone, M. B.; Shelby, S. A.; Veatch, S. L. Chem. Rev. 2017, 117, 7457.

(5) Scott, B. L.; Sochacki, K. A.; Low-Nam, S. T.; Bailey, E. M.; Luu, Q.; Hor, A.; Dickey, A. M.; Smith, S.; Kerkvliet, J. G.; Taraska,

J. W.; Hoppe, A. D. Nat. Commun. 2018, 9, 419.

(6) Wang, X.; Gao, H.; Qi, H.; Gao, Q.; Zhang, C. Anal. Chem. 2018, 9o, 3013.

(7) Rasmussen, N.; Ditzel, H. J. J. Proteome Res. 2009, 8, 5048.

(8) Kadimisetty, K.; Malla, S.; Sardesai, N. P.; Joshi, A. A.; Faria, R. C.; Lee, N. H.; Rusling, J. F. Anal. Chem. 2015, 87, 4472.

(9) Wightman, R. M.; Jankowski, J. A.; Kennedy, R. T.; Kawagoe, K. T.; Schroeder, T. J.; Leszczyszyn, D. J.; Near, J. A.; Diliberto, E., Jr.; Viveros, O. H. Proc. Natl. Acad. Sci. U.S.A. 1991, 88, 10754.

(10) Amatore, C.; Bouret, Y.; Travis, E. R.; Wightman, R. M. Angew. Chem. Int. Ed. 2ooo, 39, 1952.

(11) Amatore, C.; Arbault, S.; Bruce, D.; de Oliveira, P.; Erard, L. M.; Vuillaume, M. Chem. Eur. J. 20o1, 7, 4171.

(12) Lachgar, A.; Sojic, N.; Arbault, S.; Bruce, D.; Sarasin, A.; Amatore, C.; Bizzini, B.; Zagury, D.; Vuillaume, M. J. Virol. 1999, 73, 1447.

(13) Amatore, C.; Arbault, S.; Guille, M.; Lemaître, F. Chem. Rev. 2oo8, 108, 2585.

(14) Zhao, X.; Diakowski, P. M.; Ding, Z. Anal. Chem. 2010, 82, 8371.

(15) Takahashi, Y.; Shevchuk, A. I.; Novak, P.; Babakinejad, B.; Macpherson, J.; Unwin, P. R.; Shiku, H.; Gorelik, J.; Klenerman, D.; Korchev, Y. E.; Matsue, T. Proc. Natl. Acad. Sci. U.S.A. 2012, 109, 11540.

(16) Koch, J. A.; Baur, M. B.; Woodall, E. L.; Baur, J. E. Anal. Chem. 2012, 84, 9537.

(17) Nebel, M.; Grützke, S.; Diab, N.; Schulte, A.; Schuhmann, W. Angew. Chem. Int. Ed. 2o13, 52, 6335.

(18) Salamifar, S. E.; Lai, R. Y. Anal. Chem. 2013, 85, 9417.

(19) Clausmeyer, J.; Schuhmann, W. Trends Anal. Chem 2016, 79, 46.

(20) Soldà, A.; Valenti, G.; Marcaccio, M.; Giorgio, M.; Pelicci, P. G.; Paolucci, F.; Rapino, S. ACS Sensors 2o17, $2,1310$.

(21) Page, A.; Kang, M.; Armitstead, A.; Perry, D.; Unwin, P. R. Anal. Chem. 2017, 89, 3021.

(22) Ying, Y.-L.; Ding, Z.; Zhan, D.; Long, Y.-T. Chem. Sci. 2017, 8, 3338.

(23) Lin, T.-E.; Rapino, S.; Girault, H. H.; Lesch, A. Chem. Sci. 2018, 9, 4546.

(24) Lesch, A.; Vaske, B.; Meiners, F.; Momotenko, D.; Cortés-Salazar, F.; Girault, H. H.; Wittstock, G. Angew. Chem. Int. Ed. 2012, $51,10413$.

(25) Lin, T.-E.; Lu, Y.-J.; Sun, C.-L.; Pick, H.; Chen, J.-P.; Lesch, A.; Girault, H. H. Angew. Chem. Int. Ed. $2017,56,16498$.

(26) Zu, Y.; Ding, Z.; Zhou, J.; Lee, Y.; Bard, A. J. Anal. Chem. 2001, 73, 2153.

(27) Wilson, A. J.; Marchuk, K.; Willets, K. A. Nano Lett. 2015, 15, 6110.

(28) Dick, J. E.; Renault, C.; Kim, B.-K.; Bard, A. J. Angew. Chem. Int. Ed. 2014, 53, 11859.

(29) Bard, A. J. Electrogenerated Chemiluminescence; M. Dekker: New-York, 2004.

(30) Hesari, M.; Ding, Z. J. Electrochem. Soc. 2016, 163 , H3116.

(31) Liu, Z.; Qi, W.; Xu, G. Chem. Soc. Rev. 2015, 44, 3117.

(32) Dang, Q.; Gao, H.; Li, Z.; Qi, H.; Gao, Q.; Zhang, C. Anal. Bioanal. Chem. 2016, 408, 7067.

(33) Blackburn, G. F.; Shah, H. P.; Kenten, J. H.; Leland, J.; Kamin, R. A.; Link, J.; Peterman, J.; Powell, M. J.; Shah, A.; Talley, D. B.; Tyagi, S. K.; Wilkins, E.; Wu, T.-G.; Massey, R. J. Clin. Chem. 1991, 37, 1534.

(34) Sardesai, N.; Pan, S.; Rusling, J. Chem. Commun. 2oo9, 4968.

(35) Miao, W.; Choi, J.-P.; Bard, A. J. J. Am. Chem. Soc. 2002, 124, 14478.

(36) Sentic, M.; Milutinovic, M.; Kanoufi, F.; Manojlovic, D.; Arbault, S.; Sojic, N. Chem. Sci. 2014, 5, 2568.

(37) Danis, A. S.; Potts, K. P.; Perry, S. C.; Mauzeroll, J. Anal. Chem. 2018, 9o, 7377.

(38) Deiss, F.; LaFratta, C. N.; Symer, M.; Blicharz, T. M.; Sojic, N.; Walt, D. R. J. Am. Chem. Soc. 20o9, 131, 6088.

(39) Valenti, G.; Zangheri, M.; Sansaloni, S. E.; Mirasoli, M.; Penicaud, A.; Roda, A.; Paolucci, F. Chem. Eur. J. $2015,21,12640$.

(40) Fan, F.-R. F.; Park, S.; Zhu, Y.; Ruoff, R. S.; Bard, A. J. J. Am. Chem. Soc. 20o9, 131, 937.

(41) Zhu, M.-J.; Pan, J.-B.; Wu, Z.-Q.; Gao, X.-Y.; Zhao, W.; Xia, X.-H.; Xu, J.-J.; Chen, H.-Y. Angew. Chem. Int. Ed 2018, 57, 4010.

(42) Xu, J.; Huang, P.; Qin, Y.; Jiang, D.; Chen, H.-y. Anal. Chem. 2016, 88, 4609.

(43) Zhou, J.; Ma, G.; Chen, Y.; Fang, D.; Jiang, D.; Chen, H.-y. Anal. Chem. 2015, 87, 8138.

(44) Ma, G.; Zhou, J.; Tian, C.; Jiang, D.; Fang, D.; Chen, H. Anal. Chem. 2013, 85, 3912.

(45) Liu, G.; Ma, C.; Jin, B.-K.; Chen, Z.; Zhu, J.-J. Anal. Chem. 2018, 9o, 4801.

(46) Valenti, G.; Scarabino, S.; Goudeau, B.; Lesch, A.; Jović, M.; Villani, E.; Sentic, M.; Rapino, S.; Arbault, S.; Paolucci, F.; Sojic, N. J. Am. Chem. Soc. 2017, 139, 16830.

(47) Lu, Y.; Young, J.; Meng, Y. G. Curr. Opin. Pharmacol. 2007, 7, 541.

(48) Lu, Y.; Wong, W. L.; Meng, Y. G. J. Immunol. Methods 20o6, 314, 74.

(49) Yang, H.; Leland, J. K.; Yost, D.; Massey, R. J. Nat. Biotechnol. 1994, 12, 193.

(50) Jović, M.; Zhu, Y.; Lesch, A.; Bondarenko, A.; Cortés-Salazar, F.; Gumy, F.; Girault, H. H. J. Electroanal. Chem. 2017, 786, 69.

(51) Zhou, X.; Zhu, D.; Liao, Y.; Liu, W.; Liu, H.; Ma, Z.; Xing, D. Nat. Protocols 2014, 9, 1146.

(52) Simon, W. Curr. Protoc. Cytom. 2oo9, 48, 12.16.1.

(53) Gomperts, B. D.; Fernandez, J. M. Trends Biochem. Sci 1985, 10, 414.

This item was downloaded from IRIS Università di Bologna (https://cris.unibo.it/)

When citing, please refer to the published version. 
(54) Liu, X.; Shi, L.; Niu, W.; Li, H.; Xu, G. Angew. Chem. Int. Ed. 2007, 46, 421.

(55) Conchello, J.-A.; Lichtman, J. W. Nat. Meth. $2005,2,920$.

(56) Agard, D. A. Ann. Rev. Biophys. Bioeng. 1984, 13, 191.

(57) Keller, H. E. In Handbook of Biological Confocal Microscopy; Pawley, J., Ed.; Plenum Press: New York, 1995; Vol. 145-161.

(58) Puntheeranurak, T.; Wildling, L.; Gruber, H. J.; Kinne, R. K. H.; Hinterdorfer, P. J. Cell Sci. 20o6, 119, 2960.

(59) Giebel, K. F.; Bechinger, C.; Herminghaus, S.; Riedel, M.; Leiderer, P.; Weiland, U.; Bastmeyer, M. Biophys. J. 1999, 76, 509.

(6o) Wang, W.; Wang, S.; Liu, Q.; Wu, J.; Tao, N. Langmuir 2012, 28, 13373.

(61) Valenti, G.; Fiorani, A.; Li, H.; Sojic, N.; Paolucci, F. ChemElectroChem 2016, 3, 1990. 